\title{
Computational and Mathematical Model with Phase Change and Metal Addition Applied to GMAW
}

\author{
Alfredo dos Santos Maia Neto, Marcelo Gonçalves de Souza, Edson Alves Figueira Júnior, \\ Valério Luiz Borges, and Solidônio Rodrigues de Carvalho
}

College of Mechanical Engineering (FEMEC), Federal University of Uberlândia (UFU), Campus Santa Mônica, Bloco 1M, Av. João Naves de Ávila, No. 2121, 38408-100 Uberlândia, MG, Brazil

Correspondence should be addressed to Valério Luiz Borges; vlborges@mecanica.ufu.br

Received 14 March 2016; Revised 2 September 2016; Accepted 3 October 2016; Published 9 January 2017

Academic Editor: Mohammed Nouari

Copyright (C) 2017 Alfredo dos Santos Maia Neto et al. This is an open access article distributed under the Creative Commons Attribution License, which permits unrestricted use, distribution, and reproduction in any medium, provided the original work is properly cited.

\begin{abstract}
This work presents a 3D computational/mathematical model to solve the heat diffusion equation with phase change, considering metal addition, complex geometry, and thermal properties varying with temperature. The finite volume method was used and the computational code was implemented in $\mathrm{C}++$, using a Borland compiler. Experimental tests considering workpieces of stainless steel AISI 304 were carried out for validation of the thermal model. Inverse techniques based on Golden Section method were used to estimate the heat transfer rate to the workpieces. Experimental temperatures were measured using thermocouples type J-in a total of 07 (seven) - all connected to the welded workpiece and the Agilent 34970A data logger. The workpieces were chamfered in a $45^{\circ} \mathrm{V}$-groove in which liquid metal was added on only one weld pass. An innovation presented in this work when compared to other works in scientific literature was the geometry of the weld pool. The good relation between experimental and simulated data confirmed the quality and robustness of the thermal model proposed in this work.
\end{abstract}

\section{Introduction}

Gas metal arc welding (GMAW) is an important manufacturing process often used for joining metals. This process is characterized by producing sufficient power to provide phase change and liquid metal deposition during welding.

However, several parameters need to be adjusted to ensure a "good quality" weld bead. Some of them are voltage, current, electrode/workpiece distance, torch speed, shielding gas, electrode diameter, and electrode speed, among others. All of these parameters are interdependent, and the variation of any of them affects all others. In this work, the interest is not in the analysis of how these parameters affect the process but in predefined parameters, which produce a "good quality" weld bead, to estimate the heat transfer and calculate the temperature distribution in the welded workpiece.

Kong et al. [1] developed a numerical and experimental study of thermally induced residual stress in the hybrid laserGMA welding process. Based on numerical simulation the authors show that higher residual stress and temperature are distributed in the weld bead and surrounding heat-affected zone (HAZ). A 3D numerical model based on Finite Element was developed to simulate the joint of thin stainless steel strips with conventional V-grooved and overlap welding. A GMAW double-ellipsoid heat source model was used [2]. After cooling down, the welded plate was cut and metallurgical structure at the cross-section of the specimens was checked and the stress and groove segment were measured. Although the authors have developed a sophisticated thermal model they despised an important phenomenon: the metal phase change during welding (solid/liquid and liquid/solid). Therefore, the thermal model considers only the sensible heat portion and despises the presence of latent heat. In this case, the proposed technique calculates extremely high temperatures in the weld bead, which certainly affected the calculated stress distribution in the plates.

Heinze et al. [3] also developed a numerical model using Sysweld software to calculate residual stress and temperatures of V-grooved flat plates with overlap welding. Experimental data was used to calibrate the heat source of the simulation. 
Two aspects were considered in the temperature field adjustment. First, the cross-section geometry of the simulated weld pool was correlated with both the size and shape of the experimental macrosection of the weld seam. Second, the corresponding temperature cycles in the HAZ were correlated with the experimental measurements. Kamble and Rao [4] developed a numerical model using Ansys software. The simulations are performed on welded plates made of $60^{\circ}$ groove angle and joined together using GMAW process. The height of the semicircular bead has been imposed based on experimental data. The heat transfer thermal model was divided only into three basic modes: conduction, convection, and radiation. Based on experimental data and calculated temperatures the authors analyzed the residual stress components of the welding and concluded that the developed model was reasonably accurate. Both works $[3,4]$ also ignored the phase change phenomenon during welding.

In this work it was developed a three-dimensional own code based on the finite volume method with fixed grid techniques for diffusion controlled phase change problems [5]. The welding process of metallic flat plates with moving heat source was also investigated. The workpieces were chamfered in a $45^{\circ} \mathrm{V}$-groove where liquid metal was added during GMAW welding. Based on optimization techniques and inverse problems, the heat transfer rate and the dimensions of the welded bed were estimated. Experimental data was used to validate the results obtained in this work. Through this work it was possible to effectively identify the tridimensional geometry of the welding pool, defined as the region in which phase transition occurs (solid/liquid) and metal becomes completely liquid during gas metal arc welding. The novelty of this work when compared to the literature reports is the combination of a tridimensional thermal model with phase change and the use of inverse problems to analyze GMAW applied to the union of $\mathrm{V}$-grooved flat plates.

\section{Fundamentals: Computational and Mathematical Model}

The mathematical model proposed in this work is based on a three-dimensional thermal model with phase change and material addition. Figure 1 shows the geometry of thermal model before and after GMAW welding process.

Equation (1) represents the thermal model with phase change where the thermal properties $k(T)$ and $c(T)$ vary with temperature, as presented in Table 1 . The heat conduction equation was solved numerically using finite volumes techniques, a fully implicit procedure, and a nonregular mesh.

$$
\begin{aligned}
& \frac{\partial}{\partial x}\left(k \frac{\partial T}{\partial x}\right)+\frac{\partial}{\partial y}\left(k \frac{\partial T}{\partial y}\right)+\frac{\partial}{\partial z}\left(k \frac{\partial T}{\partial z}\right)+q^{\prime \prime \prime} \partial x \partial y \partial z \\
& =\rho c \frac{\partial T}{\partial t}+\rho L \frac{\partial f}{\partial t} .
\end{aligned}
$$

The following boundary conditions were also considered:

$$
-k \frac{\partial T}{\partial \eta_{i}}=\frac{\dot{m} L}{A},
$$

liquid metal addition in $\mathrm{V}$-groove chamfer as presented in Figure 1,

$$
-k \frac{\partial T}{\partial \eta_{i}}=h_{i}\left(T_{i}-T_{\infty}\right),
$$

in the remaining regions of the workpiece, and the initial condition

$$
T(x, y, z, t)=T_{o} \quad \text { at } t=0,
$$

where $\partial / \partial \eta$ denotes differentiation along the outward-drawn normal to the boundary surface of the workpiece, $T$ is the calculated temperature, $h$ is the heat transfer coefficient by convection, $T_{\infty}$ is the room temperature, $q^{\prime \prime \prime}$ is a moving heat generation considered constant during the welding process, and $k(T)$ and $c(T)$ are temperature dependent thermal conductivity and specific heat, respectively. The mass fraction $f$ was calculated numerically using a predictive function as presented by Voller and Brent [5].

Figure 2 shows a flowchart of the computational algorithm called direct problem.

An iterative process for each step was used to solve the numerical thermal problem. At each iteration, based on the convergence of a quadratic error function (5), the algorithm proposed in this work updates the thermal properties and the mass fraction. Basically, the direct problem is treated as linear at each iteration. However, at each step, the computational algorithm provides a nonlinear solution of the thermal problem. The code was developed in $\mathrm{C}++$ Builder 5.0.

In this work, the energy supplied to the workpiece was divided into two fractions: one resulting from the welding torch (heat generation) and other coming from liquid metal deposition. The heat generation was estimated using inverse heat conduction techniques. Based on the Golden Section method, the goal was to estimate a constant value for $q^{\prime \prime \prime}$ (1) that minimizes a quadratic error function based on experimental and calculated temperatures as presented in

$$
S=\sum_{j}^{\mathrm{ns}} \sum_{i}^{\mathrm{nt}}\left(T_{\exp }-T_{\text {cal }}\right)^{2} .
$$

An "extra mesh" was implemented in the thermal model to simulate the liquid metal deposition during welding. Figure 3 presents the region chamfered in V-groove upon which the "extra mesh" was added. It is noteworthy that the width and the top surface shape of the weld bead, as well as the metal deposition rate, were measured after performing experimental welding process, as presented in Figure 1(c), and implemented in computational algorithm.

The direct problem simulates at each time step liquid metal deposition at $2500^{\circ} \mathrm{C}$ with mass fraction $f=1$. The thermal properties of liquid metal above its melting point were considered, as shown in Hirata et al. [6], Figure 4.

\section{Experimental Assembly}

To validate the computational algorithm, an experimental bench of testes was assembled in the welding laboratory of 
TABLE 1: Thermal physical properties of stainless steel AISI 304 and other properties.

\begin{tabular}{|c|c|c|c|}
\hline Symbol & Property & Value & Unit \\
\hline$T_{\text {sat }}$ & Saturation temperature & 1400 & {$\left[{ }^{\circ} \mathrm{C}\right]$} \\
\hline$\rho$ & Density & 7200 & {$\left[\mathrm{~kg} / \mathrm{m}^{3}\right]$} \\
\hline$L$ & Latent heat of fusion & 265200 & {$[\mathrm{~J} / \mathrm{kg}]$} \\
\hline$k$ & Thermal conductivity & $\begin{array}{l}k=14.386+1.71810^{-2} T-2.57810^{-6} T^{2} \text { for } T \leq 1400 \\
k=31.5 \text { for } T>1400\end{array}$ & {$\left[\mathrm{~W} / \mathrm{m}^{\circ} \mathrm{C}\right]$} \\
\hline$c$ & Specific heat & $\begin{array}{l}c=474.1+0.2358 T-5.215010^{-5} T^{2} \text { para } T \leq 1400 \\
c=812.0 \text { para } T>1400\end{array}$ & {$\left[\mathrm{~J} / \mathrm{kg}^{\circ} \mathrm{C}\right]$} \\
\hline$h$ & Convection coefficient & 30 & {$\left[\mathrm{~W} / \mathrm{m}^{2 \circ} \mathrm{C}\right]$} \\
\hline$T_{\infty}$ & Room temperature & 30 & {$\left[{ }^{\circ} \mathrm{C}\right]$} \\
\hline
\end{tabular}

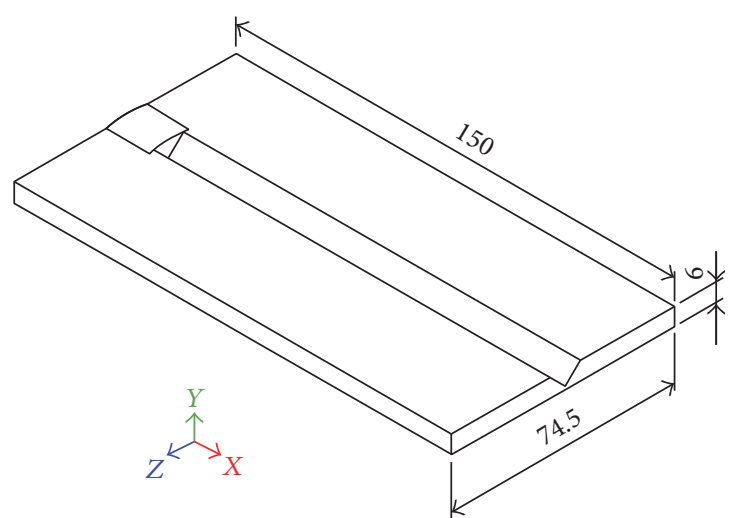

(a)

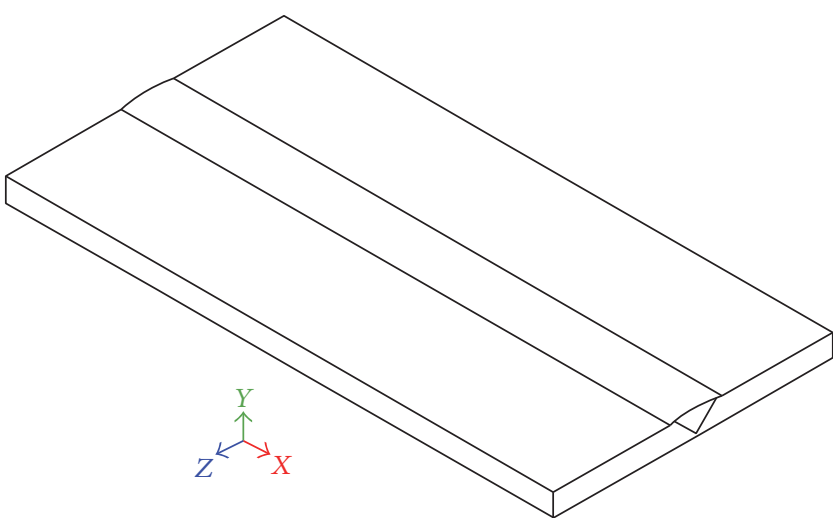

(b)

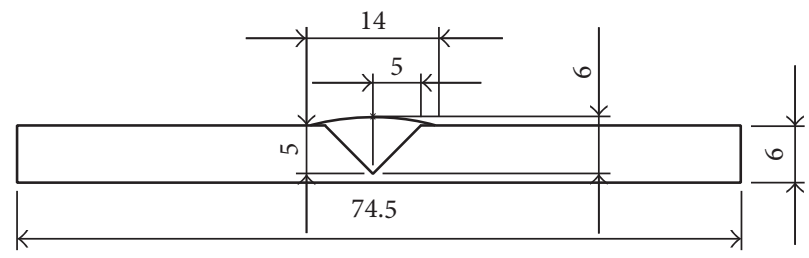

(c)

FIGURE 1: Three-dimensional thermal model (dimensions in mm): (a) MIG welding process in progress, (b) workpiece after welding process, and (c) cut in $y z$ axis.

the Federal Institute of Education, Science and Technology of Maranhão, Brazil, as presented in Figure 5.

The workpieces were manufactured from metallic flat plates of austenitic stainless steel AISI 304, duly certified as to its composition. The objective was to simulate the union of two metallic flat plates. Therefore, workpieces with a Vgroove (with depth of $0.005[\mathrm{~m}]$ and $45^{\circ}$ ) were used. The dimensions of each workpiece were $a=0.0745[\mathrm{~m}] ; b=$ $0.150[\mathrm{~m}] ; c=0.006[\mathrm{~m}]$. This procedure facilitated the experimental assembly and installation of the workpiece in the support as shown in Figure 5. The support used in the experiments has four screws with conical ends in order to fix the workpiece and minimize heat conduction between metal parts.

The experiments were performed using GMAW welding in inverse polarity: positive electrode. A weld rectifier LAI ESAB 400 was used in continuous mode. The arc current is set at $160 \mathrm{~A}$, and arc voltage is set at $24 \mathrm{~V}$.
A stainless steel (ER308LSi AWS A5.9) nude wire with $0.0012[\mathrm{~m}]$ of diameter was used as additional metal. The speed of wire feed was $0.066 \mathrm{~m} / \mathrm{s}$. The Stargold Flex (argon $+3 \%$ oxygen) at $4.17 \times 10^{-6}\left[\mathrm{~m}^{3} / \mathrm{s}\right]$ was used as protection gas. The welding speed in $x$-axis direction was kept constant at $0.0037[\mathrm{~m} / \mathrm{s}]$. Table 2 summarizes the welding parameters adopted in the present work.

Run-on and run-off plates were positioned near to the workpiece where the electric arc was turned on and turned off during the welding process, as shown in Figure 5. This procedure and the welding parameters adopted minimize interferences related to ignition/stability of the electric arc and keep constant the heat transfer rate and the liquid metal deposition during welding of the workpiece. It is important to emphasize that the sacrificial plates were not in direct contact with the workpiece. They were separated by enough distance to ensure stable welding conditions and the boundary conditions proposed for the thermal model (3). 


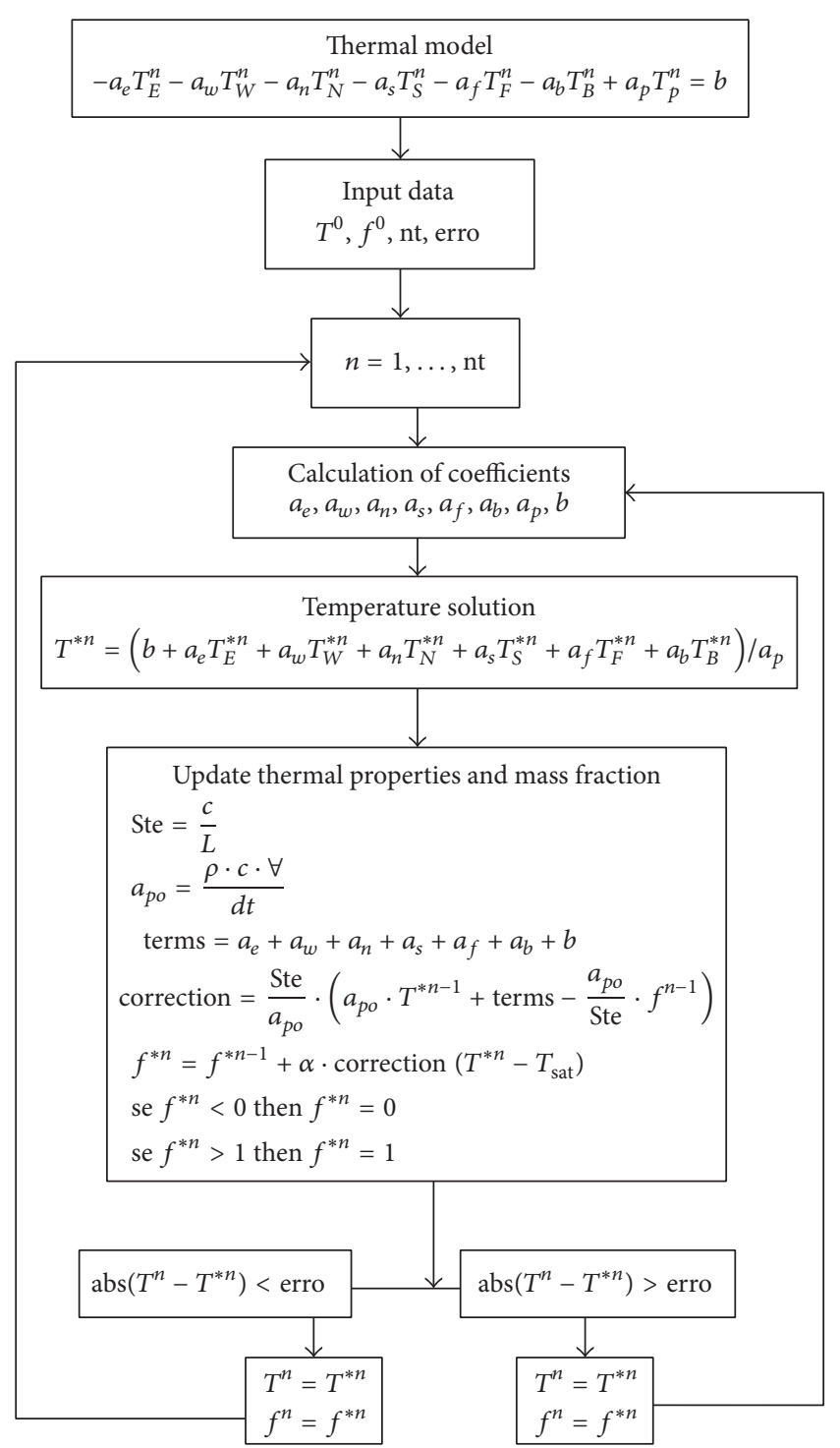

FIgURE 2: Direct problem flowchart.

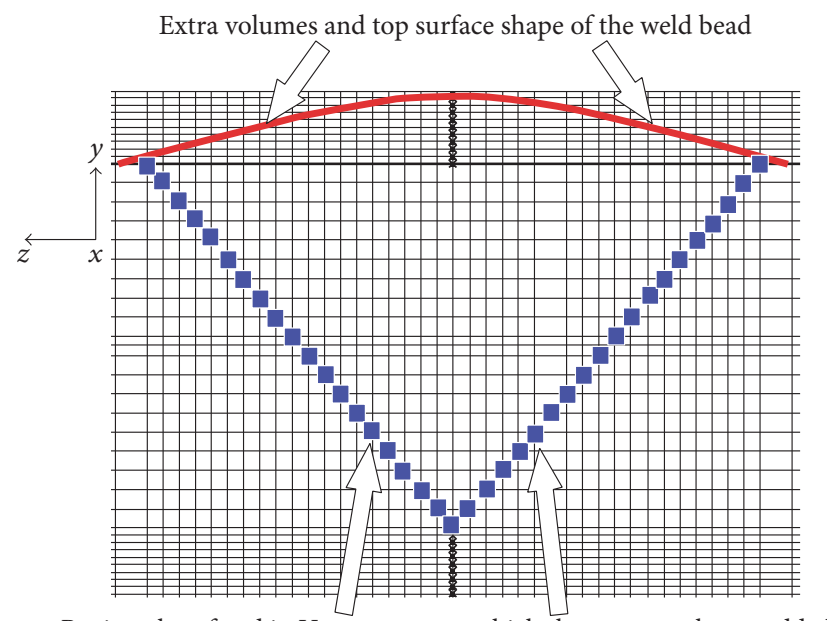

Region chamfered in V-groove upon which the extra mesh was added

FIGURE 3: Extra mesh in $y z$ plane section.

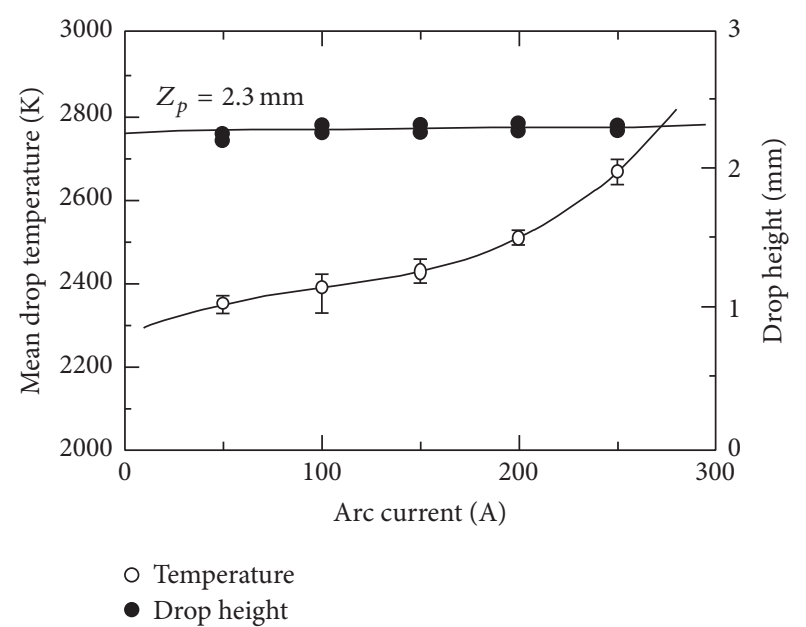

FIGURE 4: Temperature of liquid metal [6].

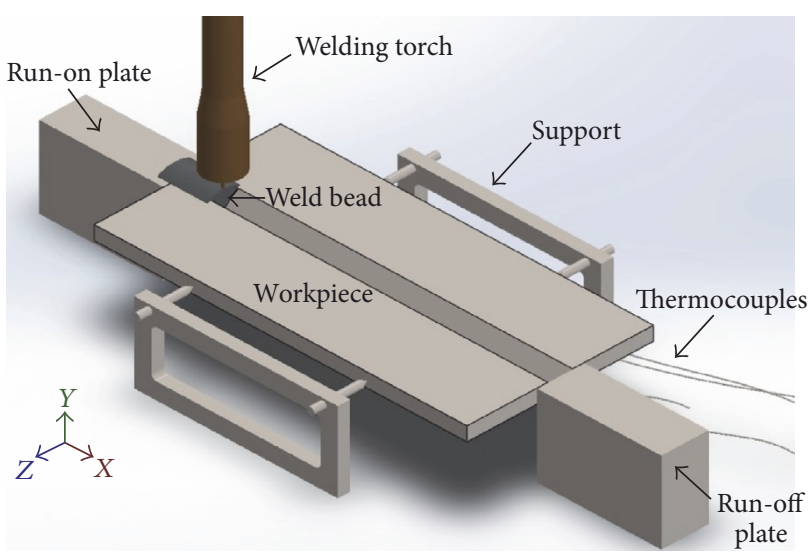

FIgURE 5: Scheme of the experimental bench of tests.

TABLE 2: Welding parameters.

\begin{tabular}{lccc}
\hline Symbol & Property & Value & Unit \\
\hline$V$ & Welding voltage & 24 & {$[\mathrm{~V}]$} \\
$I$ & Welding current & 160 & {$[\mathrm{~A}]$} \\
$d_{\text {wire }}$ & Wire diameter & 0.0012 & {$[\mathrm{~m}]$} \\
$v$ & Torch speed & 0.0037 & {$[\mathrm{~m} / \mathrm{s}]$} \\
$v_{\text {wire }}$ & Wire feed speed & 0.066 & {$[\mathrm{~m} / \mathrm{s}]$} \\
$Q$ & Gas flow & $4.17 \times 10^{-6}$ & {$\left[\mathrm{~m}^{3} / \mathrm{s}\right]$} \\
\hline
\end{tabular}

Experimental temperatures were measured by 7 thermocouples type J located in the opposite surface of the weld bead, according to the coordinates presented in Table 3. A data acquisition system Agilent 34970A connected to a computer was used to analyze experimental data.

\section{Results}

The results presented in this work were calculated by software developed in Heat and Mass Transfer Laboratory (LTCM), at the Federal University of Uberlândia, Borges et al. [7]. This 


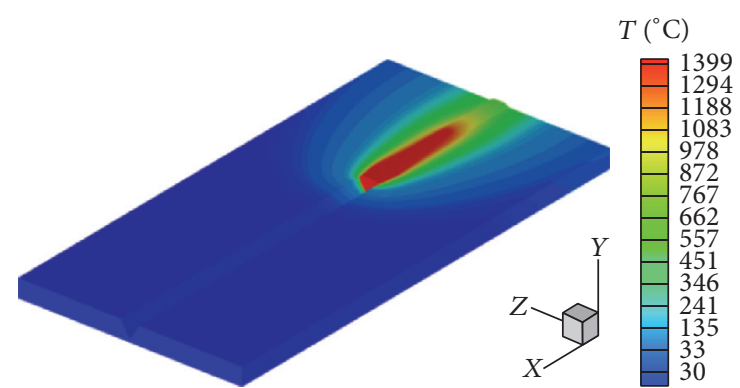

(a)

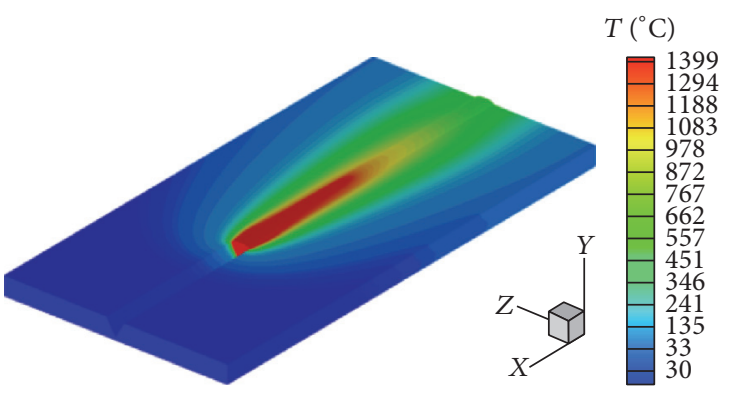

(b)

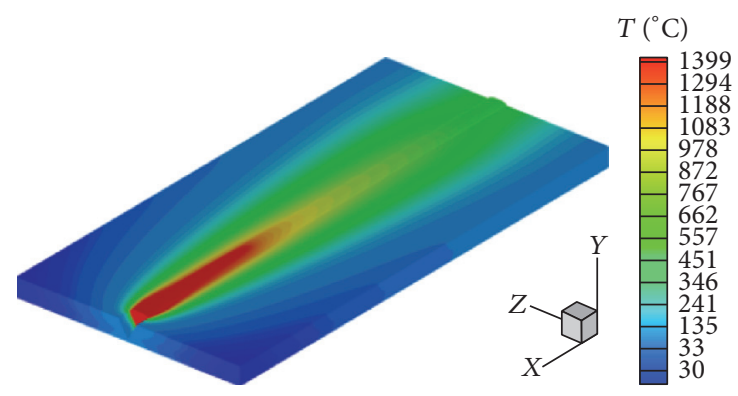

(c)

Figure 6: Temperature at the top surface of the welded plate after (a) 12 [s]; (b) 24 [s]; (c) 36 [s] of welding.

TABLE 3: Thermocouples positions in the workpiece.

\begin{tabular}{lccc}
\hline Thermocouples & $x[\mathrm{~m}]$ & $y[\mathrm{~m}]$ & $z[\mathrm{~m}]$ \\
\hline$T_{1}$ & 0.0100 & 0 & 0.04600 \\
$T_{2}$ & 0.0305 & 0 & 0.02780 \\
$T_{3}$ & 0.0510 & 0 & 0.04600 \\
$T_{4}$ & 0.0700 & 0 & 0.02780 \\
$T_{5}$ & 0.0900 & 0 & 0.04600 \\
$T_{6}$ & 0.1100 & 0 & 0.02780 \\
$T_{7}$ & 0.1315 & 0 & 0.04600 \\
\hline
\end{tabular}

software was previously validated in simulations of threedimensional problems involving determination of thermal properties [7] and thermal simulation of a drilling process [8].

Figure 6 shows the temperature at the top surface of the welded plate after (a) 12 [s]; (b) 24 [s]; (c) 36 [s] of welding.

Figure 7 shows details about the tridimensional geometry of the weld pool estimated after (a) 12 [s]; (b) 24 [s]; (c) 36 [s], where only liquid metal was observed.
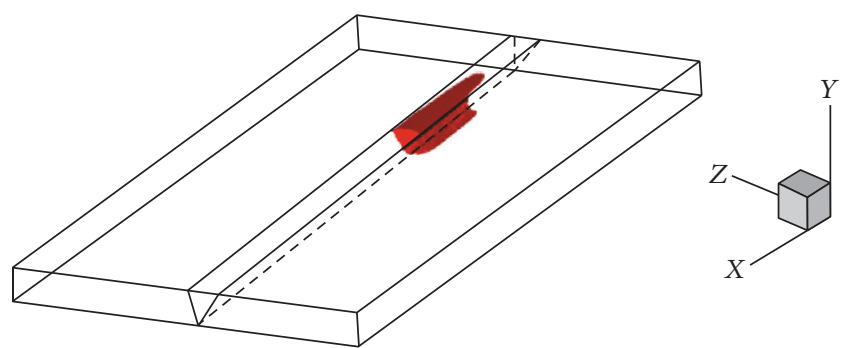

(a)
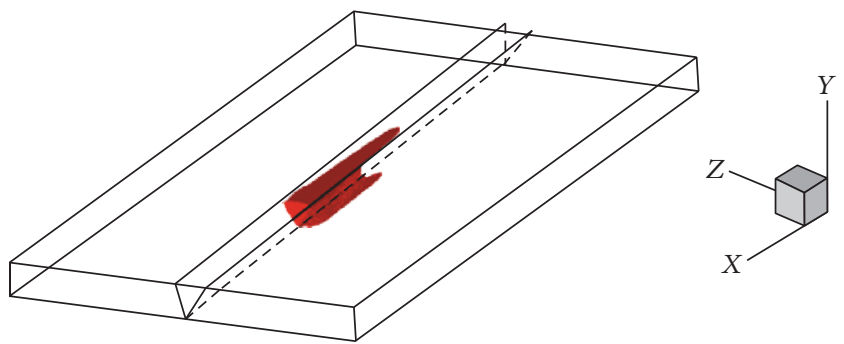

(b)
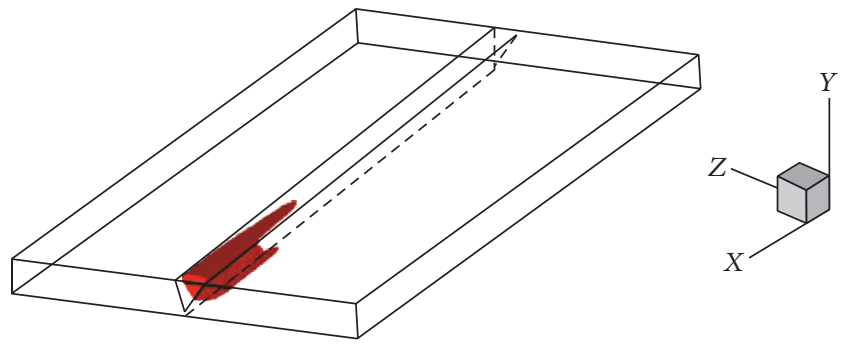

(c)

FIGURE 7: Tridimensional geometry of the weld pool estimated after (a) $12[\mathrm{~s}]$; (b) 24 [s]; (c) $36[\mathrm{~s}]$.

TABLE 4: Thermal efficiency of the MIG welding process.

\begin{tabular}{lccc}
\hline & $\begin{array}{c}\text { Heat } \\
\text { effectively } \\
\text { Power source: }\end{array}$ & $\begin{array}{c}\text { Energy as } \\
\text { delivered to } \\
\text { liquid metal } \\
\text { LAI ESAB 400 } \\
E_{T}=V \cdot I[\mathrm{~W}]\end{array}$ & $\begin{array}{c}\text { estimated } \\
\text { deposition }\end{array}$ \\
$\begin{array}{lccc}E_{i}=\dot{m} L[\mathrm{~W}] \\
\end{array}$ & $\begin{array}{c}E_{i i}= \\
q^{\prime \prime \prime} \partial x \partial y \partial z \\
{[\mathrm{~W}]}\end{array}$ & $\begin{array}{c}\eta=\left(E_{i}+E_{i i}\right) / E_{T} \\
\text { process }\end{array}$ \\
\hline 3840 & 1041 & 2519 & 92,71 \\
\hline
\end{tabular}

The thermal efficiency was estimated as presented in Table 4 based on useful energy (heat generation and liquid metal deposition) and the total power supplied by the weld rectifier LAI ESAB 400.

It is observed in Table 4 that the value obtained for the thermal efficiency is in accordance with Pépe et al. [9], which proves the effectiveness and robustness of the thermal model proposed in the present work.

Through the analysis of articles available in the scientific literature, it can be seen that some adopt Goldak's doubleellipsoid heat flux distribution as a predefined geometry for the weld pool [10]. Others use experimental surface temperatures and contours to define the topology geometry of the 
weld pool [11]. Mathematical models based on heat transfer and fluid flow were also applied to study the gas metal arc welding process and the weld pool [9]. However, predefined heat source with Gaussian distribution and (2D) asymmetric model were examples of simplifications adopted by some authors in order to solve the numerical heat diffusion equation.

In this work the geometry of the weld pool was not imposed, it was estimated based on (1) to (4) and experimental data, such as width of the weld bead, liquid metal deposition, and speed of the welding torch. The combination of such parameters and inverse problems provided the threedimensional weld pool shown in Figure 7. It is emphasized that similar results were not found in scientific literature. Most of the researchers use commercial software (Ansys, Fluent, Sysweld, Comsol, and others) and even then adopt a mathematical equation that disregards the effects of phase change inherent to the welding process: solid/liquid and liquid/solid.

Figure 8 shows the liquid mass fraction after (a) 12 [s]; (b) 24 [s]; (c) 36 [s] of welding and (d) comparison between experiment and calculated data.

In both figures it can be seen that the weld pool reaches the surface opposite the welding torch, which proves that the thermal model proposed in this work is in agreement with the welding experiment.

Figure 9 shows the comparison between experimental and calculated temperatures.

Uncertainties due to coordinates of the thermocouples, beginning and ending of the welding process, welding torch location in relation to the center line of the $\mathrm{V}$-groove region, were expected and resulted in deviations between experimental and calculated values.

\section{Conclusions}

In this work a $3 \mathrm{D}$ computational/mathematical model was developed to solve the heat diffusion equation with phase change, considering metal addition, complex geometry, and thermal properties varying with temperature.

To validate the computational algorithm, an experimental bench of testes was assembled. Metal flat plates with a Vgroove were used where liquid metal was added on only one weld pass.

The Golden Section technique was used to estimate the heat transfer rate in the welding process, as well as the geometry of the weld bead and the thermal efficiency of the process. The temperatures were measured by thermocouples positioned at the bottom surface of the welded plate and small deviations were observed between experimental and calculated data. Subsequently the thermal efficiency of the process was calculated resulting in $92,71 \%$, value which is consistent with literature report.

Literature review revealed that researchers usually ignore the phase change phenomenon when modeling welding processes, especially if the thermal problem is tridimensional and thermal properties vary with temperature. The authors investigated in this work used commercial software (Ansys

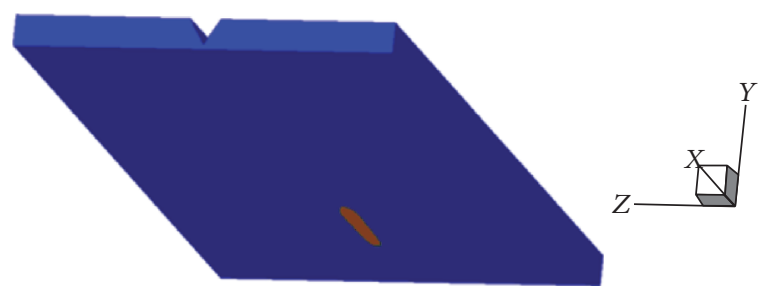

(a)

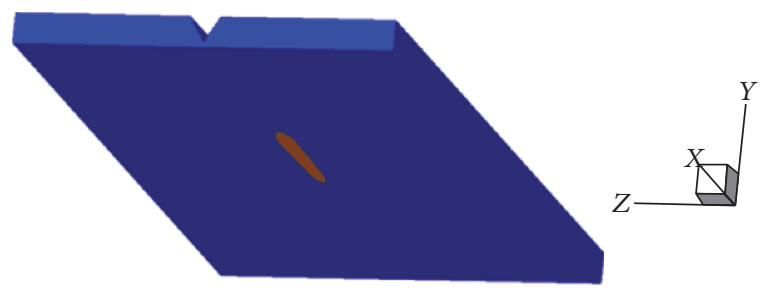

(b)

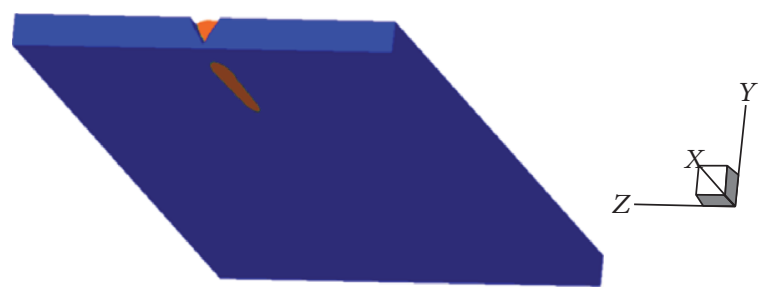

(c)

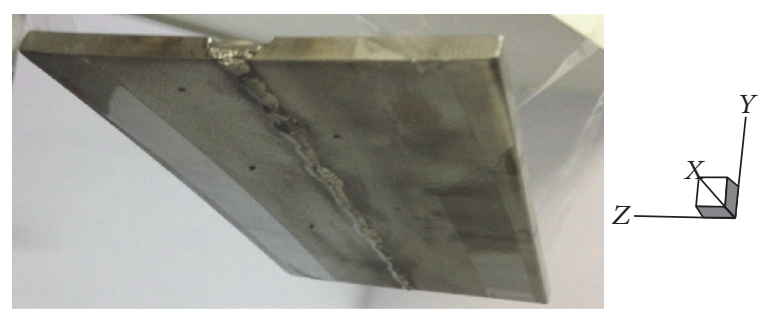

(d)

FIGURE 8: Liquid mass fraction at the bottom surface of the welded plate after (a) 12 [s]; (b) 24 [s]; (c) 36 [s] of welding and (d) comparison between experiment and calculated data.

and Sysweld) and they do not consider phase change in their thermal analysis. The thermal model developed in this work revealed that, during heating, the absence of latent heat term makes the temperature increase continuously, which provides extremely high temperature values, outside the range expected for the welding thermal problem.

The thermal problem proposed in this work was based on diffusion of controlled phase change problems [5]. In this sense, the thermal problem presented in (1) is nonlinear and an iterative process at each time step is required. Basically, during heating, when a region of the material reaches temperatures close to the melting point, the iterative process presented in Figure 2 starts. It keeps the weld pool temperature equal to the melting temperature. When such region melts completely, that is, the mass fraction " $f$ " reaches unity values, the enthalpy porosity technique allows the temperature of the weld pool to increase to values greater than the melting point. 


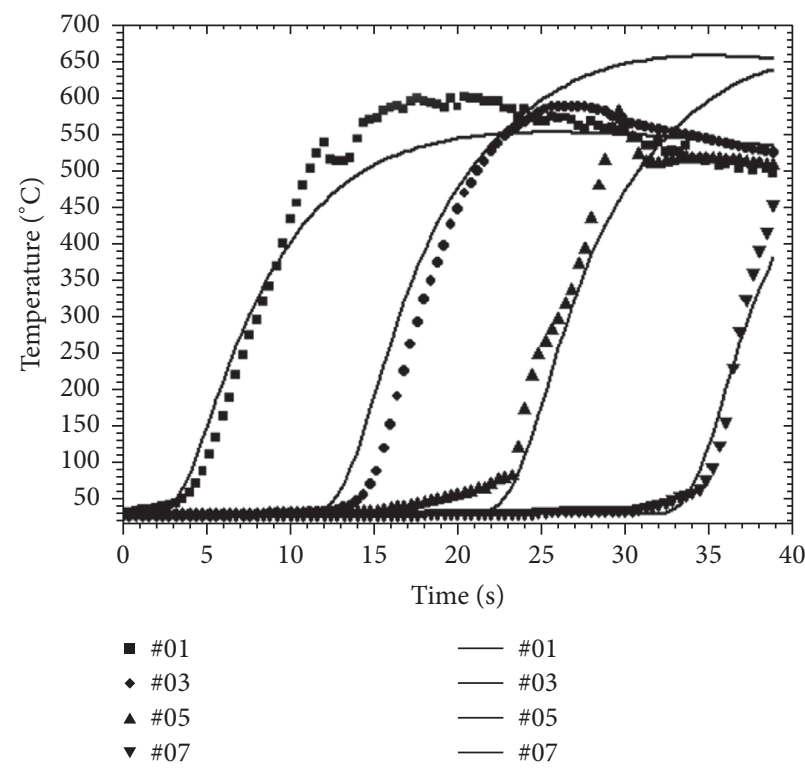

(a)

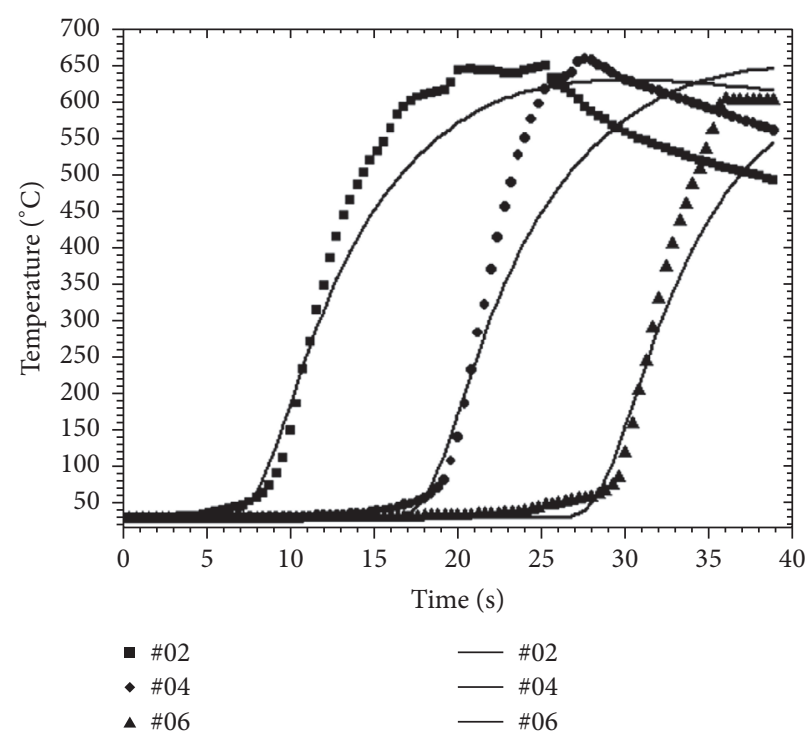

(b)

FIGURE 9: Comparison between experimental (dotted line) and calculated (continuous line) temperatures: (a) odds and (b) evens thermocouples.

Finally, it is concluded that the technique adopted in this work is physically more realistic and can provide better results when compared to those presented in the literature report.

\section{Nomenclature}

$\begin{array}{ll}x: & \text { Cartesian coordinate, } \mathrm{m} \\ y: & \text { Cartesian coordinate, } \mathrm{m} \\ z: & \text { Cartesian coordinate, } \mathrm{m} \\ a: & \text { Length axis } x, \mathrm{~m} \\ b: & \text { Length axis } y, \mathrm{~m} \\ c: & \text { Length axis } z, \mathrm{~m} \\ k: & \text { Thermal conductivity, } \mathrm{W} / \mathrm{m}^{\circ} \mathrm{C} \\ c: & \text { Specific heat, } \mathrm{J} / \mathrm{kg}^{\circ} \mathrm{C} \\ \rho: & \text { Density, kg/m }{ }^{3} \\ f: & \text { Mass fraction } \\ L: & \text { Latent heat of fusion, } \mathrm{J} / \mathrm{kg} \\ T: & \text { Temperature, }{ }^{\circ} \mathrm{C} \\ T_{\infty}: & \text { Room temperature, }{ }^{\circ} \mathrm{C} \\ h: & \text { Heat transfer coefficient by convection, } \mathrm{W} / \mathrm{m}^{2 \circ} \mathrm{C} \\ t: & \text { Time, } \mathrm{s} \\ q^{\prime \prime \prime}: & \text { Heat generation, } \mathrm{W} / \mathrm{m}^{3} \\ T_{\text {sat }}: & \text { Melting temperature, }{ }^{\circ} \mathrm{C} \\ E_{i}: & \text { Melting of the additional metal, } \mathrm{W} \\ E_{i i}: & \text { Losses to the environment, W } \\ E_{T}: & \text { Welding energy, } \mathrm{W} \\ V: & \text { Welding voltage, } \mathrm{V} \\ I: & \text { Welding current, } \mathrm{A} \\ d_{\text {arame }}: & \text { Wire diameter, mm } \\ \mathrm{Q}: & \text { Gas flow, } 1 / \mathrm{h} \\ \forall: & \text { Volume, }{ }^{3} \\ T_{\text {exp }}: & \text { Experimental temperatures, }{ }^{\circ} \mathrm{C} \\ T_{\text {cal }}: & \text { Calculated temperatures, }{ }^{\circ} \mathrm{C}\end{array}$

S: Quadratic error function

ns: Number of thermocouples

nt: Number of data

A: $\quad$ Area, $\mathrm{m}^{2}$

$v$ : Torch speed, $\mathrm{mm} / \mathrm{min}$

$v_{\text {wire }}$ : Wire feed speed, $\mathrm{m} / \mathrm{min}$

$\eta$ : Thermal efficiency.

\section{Disclosure}

The authors are solely responsible for the content of the printed material included in this work.

\section{Competing Interests}

The authors declare that there is no conflict of interests regarding the publication of this paper.

\section{Acknowledgments}

The team of the Transfer of Heat and Mass Laboratory of the Federal University of Uberlândia thanks the funding agencies: CAPES, CNPq, FAPEMA, and FAPEMIG and the Federal Institute of Maranhão (IFMA) for the financial support and assistance in carrying out the experiments.

\section{References}

[1] F. Kong, J. Ma, and R. Kovacevic, "Numerical and experimental study of thermally induced residual stress in the hybrid laserGMA welding process," Journal of Materials Processing Technology, vol. 211, no. 6, pp. 1102-1111, 2011. 
[2] J. Goldak, A. Chakravarti, and M. Bibby, "A new finite element model for welding heat sources," Metallurgical Transactions B, vol. 15, no. 2, pp. 299-305, 1984.

[3] C. Heinze, C. Schwenk, and M. Rethmeier, "Numerical calculation of residual stress development of multi-pass gas metal arc welding," Journal of Constructional Steel Research, vol. 72, pp. 12-19, 2012.

[4] A. G. Kamble and R. V. Rao, "Experimental investigation on the effects of process parameters of GMAW and transient thermal analysis of AISI321 steel," Advances in Manufacturing, vol. 1, no. 4, pp. 362-377, 2013.

[5] V. R. Voller and A. D. Brent, "Investigation of fixed grid techniques for convection/diffusion controlled phase change problems," in Proceedings of the 6th International Conference on Numerical Method in Thermal Problems, Swansea, UK, 1989.

[6] Y. Hirata, M. Onda, H. Nagaki, and T. Ohji, "In-situ measurement of metal drop temperature in GMA short-circuiting welding," Journal of High Temperature Society, vol. 30, no. 3, pp. 140147, 2004.

[7] V. L. Borges, P. F. B. Sousa, and G. Guimarães, "Experimental determination of thermal conductivity and diffusivity using a partially heated surface method without heat flux transducer," Inverse Problems in Science \& Engineering, vol. 16, no. 8, pp. 1047-1067, 2008.

[8] P. F. B. De Sousa, V. L. Borges, I. C. Pereira, M. B. Da Silva, and G. Guimarães, "Estimation of heat flux and temperature field during drilling process using dynamic observers based on Green's function," Applied Thermal Engineering, vol. 48, pp. 144154, 2012.

[9] N. Pépe, S. Egerland, P. A. Colegrove, D. Yapp, A. Leonhartsberger, and A. Scotti, "Measuring the process efficiency of controlled gas metal arc welding processes," Science and Technology of Welding \& Joining, vol. 16, no. 5, pp. 412-417, 2011.

[10] H. G. Kraus, "Experimental measurement of thin plate 304 stainless steel GTA weld pool surface temperatures," Welding Journal, vol. 66, no. 12, 1987.

[11] I. S. Kim and A. Basu, "A mathematical model of heat transfer and fluid flow in the gas metal arc welding process," Journal of Materials Processing Technology, vol. 300, no. 3-4, pp. 17-24, 1998. 


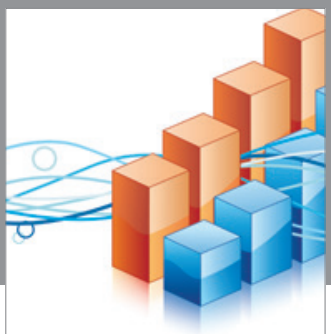

Advances in

Operations Research

vatem alat4

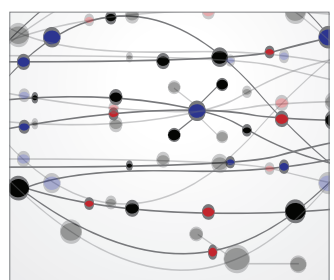

\section{The Scientific} World Journal
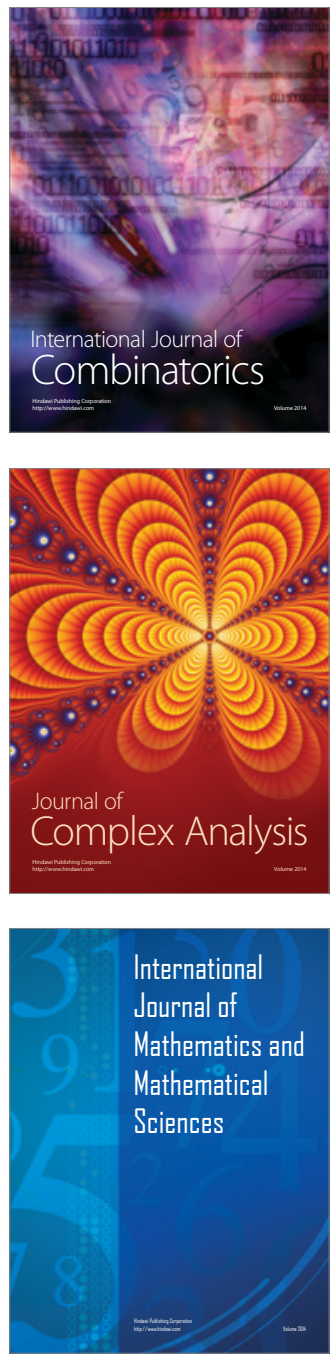
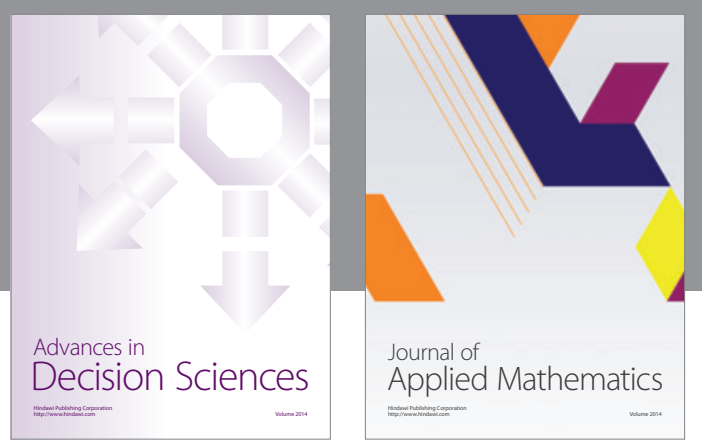

Algebra

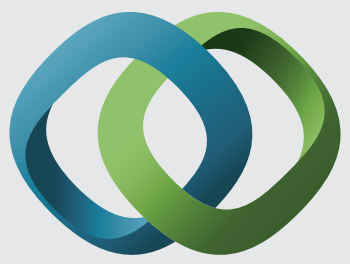

\section{Hindawi}

Submit your manuscripts at

https://www.hindawi.com
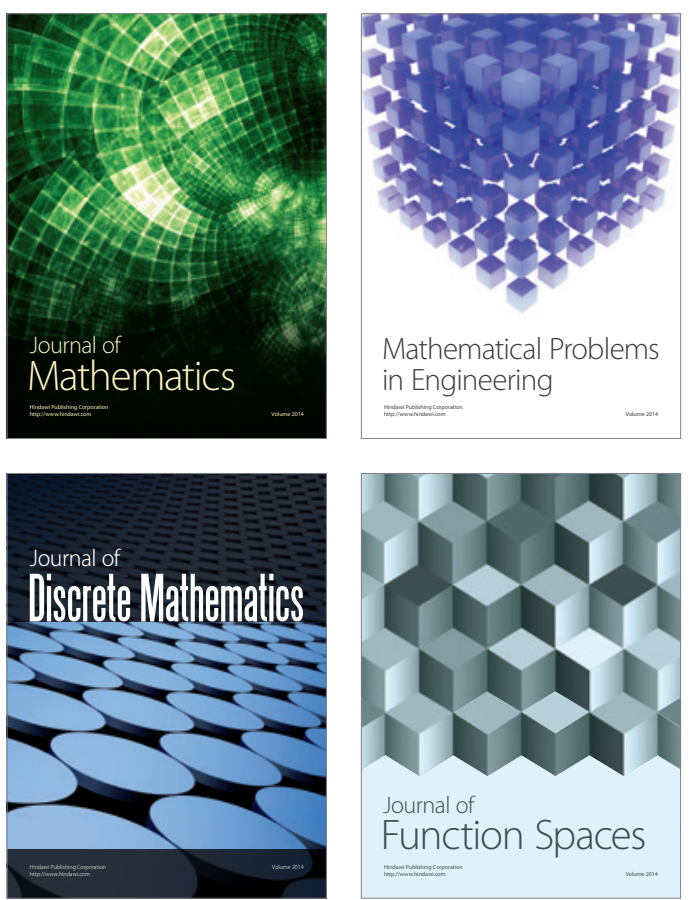

Mathematical Problems in Engineering
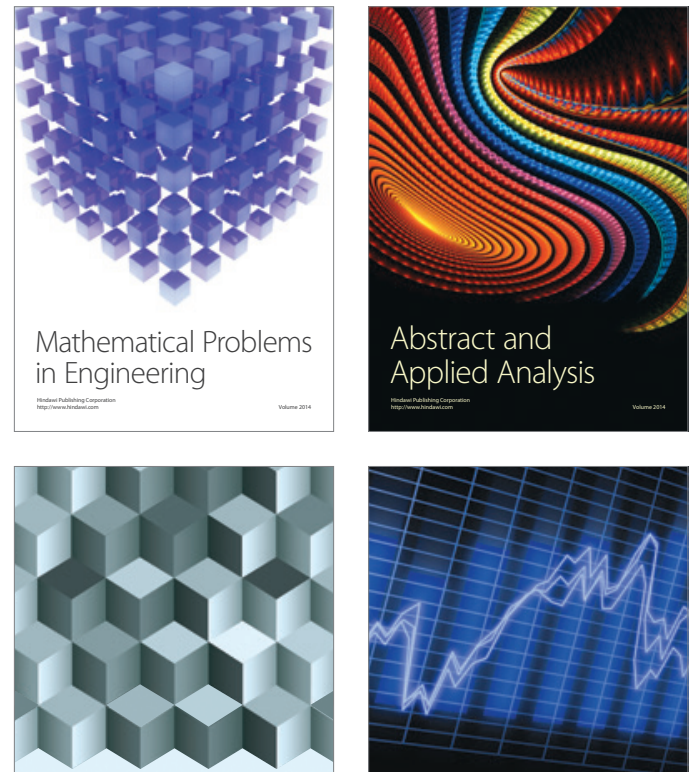

Journal of

Function Spaces

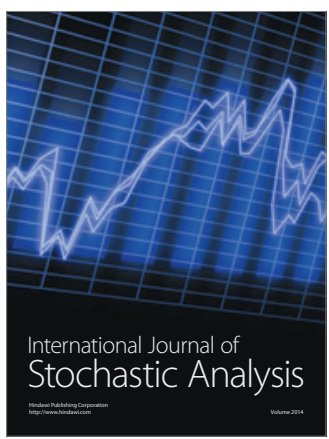

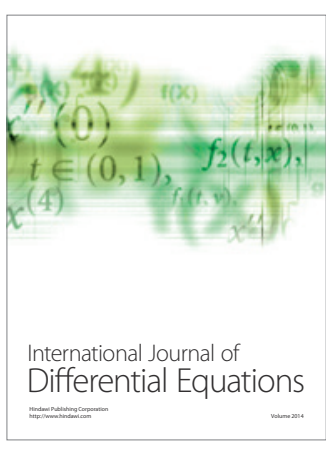
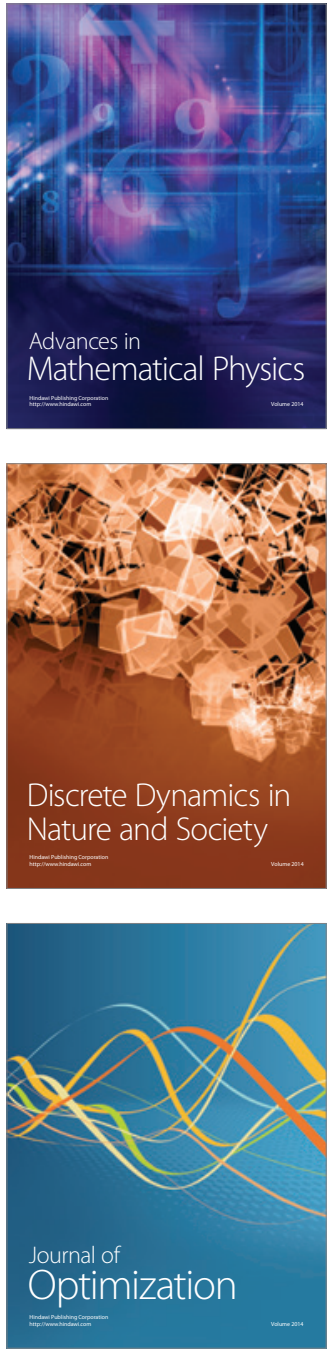